\title{
Health Benefits Due to Reduction in Respirable Particulates during COVID-19 Lockdown in India
}

Aerosol and Air Quality Research

Special Issue:

Special Issue on COVID-19 Aerosol Drivers, Impacts and Mitigation (XIII)

\section{OPEN ACCESS}

Received: July 29, 2020

Revised: December 30, 2020

Accepted: December 30, 2020

${ }^{*}$ Corresponding Author:

anubha@iitk.ac.in

\section{Publisher:}

Taiwan Association for Aerosol Research

ISSN: $1680-8584$ print

ISSN: 2071-1409 online

(c) Copyright: The Author(s). This is an open access article distributed under the terms of the Creative Commons Attribution License (CC BY 4.0), which permits unrestricted use, distribution, and reproduction in any medium, provided the original author and source are cited.

\section{Anubha Goel ${ }^{1,2^{*}}$, Pallavi Saxena ${ }^{3}$, Saurabh Sonwani ${ }^{4}$, Shubham Rathi ${ }^{1}$, Ananya Srivastava ${ }^{5}$, Akash Kumar Bharti ${ }^{6}$, Supreme Jain ${ }^{1}$, Shubhanshi Singh ${ }^{1}$, Anuradha Shukla ${ }^{7}$, Anju Srivastava ${ }^{8}$}

\author{
${ }^{1}$ Department of Civil Engineering, Indian Institute of Technology Kanpur, Kanpur 208016, India \\ ${ }^{2}$ Centre for Environmental Science and Engineering, Indian Institute of Technology Kanpur, \\ Kanpur 208016, India \\ ${ }^{3}$ Department of Environmental Sciences, Hindu College, University of Delhi, University Enclave, \\ Delhi 110007, India \\ ${ }^{4}$ Department of Environmental Studies, Zakir Husain Delhi College, University of Delhi, \\ Jawaharlal Nehru Marg, New Delhi 110002, India \\ ${ }^{5}$ Department of Economics, Hindu College, University of Delhi, University Enclave, Delhi \\ 110007, India \\ ${ }^{6}$ Department of Mathematics, Hindu College, University of Delhi University Enclave, Delhi \\ 110007, India \\ ${ }^{7}$ Transport Planning and Environment Division, CSIR-Central Road Research Institute, New Delhi \\ 110025, India \\ ${ }^{8}$ Department of Chemistry, Hindu College, University of Delhi, University Enclave, Delhi 110007, \\ India
}

\section{ABSTRACT}

To control the spread of the coronavirus (COVID-19) pandemic, the Government of India imposed various phases of lockdown starting from the third week of March 2020. Improvement in city air quality has emerged as a benefit of this lockdown in India. The objective of this paper is to quantify the health benefits due to this lockdown. $\mathrm{PM}_{2.5}$ concentrations in nonattainment cities (NACs) in Uttar Pradesh and the Delhi-National Capital Region (NCR) in North India were studied. Data from prelockdown and the various lockdown phases were compared, with 2019 as a benchmark. Compared with those in 2019, the $\mathrm{PM}_{2.5}$ concentrations during lockdown Phase 1 were approximately $44.6 \%$ lower for cities in Uttar Pradesh and approximately $58.5 \%$ lower for the Delhi-NCR. The health impacts of particle inhalation were quantified using the multiple-path particle dosimetry and AirQ+ models, which revealed that the most considerable improvement was during lockdown Phase 1. Among the prelockdown and lockdown phases, Phase 1 exhibited the minimum PM2.5 concentration and thus the greatest health benefits. For the selected cities, the concentration of particle deposition in the tracheobronchial region of human lungs showed its maximum reduction during lockdown Phase $1(30.14 \%)$. Furthermore, the results highlighted a decrease of 29.85 deaths per 100,000 persons during lockdown Phase 1 , primarily due to the reduction in $\mathrm{PM}_{2.5}$ concentrations. This quantification of the health benefits due to a decrease in $\mathrm{PM}_{2.5}$ may help policymakers implement suitable control measures, especially for NACs, where the respirable particulate matter concentrations remain very high.

Keywords: PM2.5, Nonattainment city, AirQ+, COVID-19, Health benefit quantification

\section{INTRODUCTION}

Coronavirus disease 2019 (COVID-19) was first reported in Wuhan, China, in December 2019 and is currently the most severe global health pandemic of the twenty-first century. The World 
Health Organization (WHO) declared COVID-19 a pandemic on 11 March 2020. By 31 May 2020, the total number of cases reported worldwide was approximately 6,258,158, with 3,021,245 active cases (48\%) and 2,859,906 recovered or discharged patients (46\%) (Worldometer, 2020). In India, the first infection was recorded on 30 January 2020; by 31 May 2020, the number of infections had increased to 190,609 (with 49\% active cases) (Worldometer, 2020). Governments worldwide closed their borders and imposed complete or partial lockdowns to control the spread of the disease. A $90 \%$ reduction in mobility yielded a $30 \%$ decline in $\mathrm{NO}_{2}$ emissions in major global population centers (e.g., China and the United States; Muhammad et al., 2020). During the lockdown imposed in India, $\mathrm{NO}_{2}$ emissions decreased by $17 \%$ (Metya et al., 2020) and aerosol optical depth decreased by nearly $45 \%$ (Ranjan et al., 2020). Compared with the prelockdown period, Tobías et al. (2020) reported a 28\%-31\% decline in $\mathrm{PM}_{10}$ concentrations in Barcelona, Spain. Declines of approximately $30 \%$ in $\mathrm{PM}_{2.5}$ and $\mathrm{PM}_{10}$ concentrations were also observed in Malaysia (Kanniah et al., 2020).

In India, a complete nationwide lockdown was implemented for a total of 68 days through four phases, from 25 March to 31 May 2020. Jain and Sharma (2020) compared the concentrations of criteria air pollutants between prelockdown (10-20 March 2020) and lockdown (25 March-6 April) for five Indian megacities, namely Delhi, Mumbai, Chennai, Kolkata, and Bangalore. They reported declines of $14 \%$ (Chennai) to $41 \%$ (Delhi) in $\mathrm{PM}_{2.5}$ for the lockdown period. Moreover, other studies have estimated $>50 \%$ reductions in $\mathrm{PM}_{2.5}$ and $\mathrm{PM}_{10}$ concentrations in cities such as Delhi, along with reductions of approximately $53 \%$ in $\mathrm{NO}_{2}$ concentrations and approximately $30 \%$ in CO concentrations during lockdown (Mahato et al., 2020).

The significant decrease in air pollution is a major positive outcome of the COVID-19 lockdown. Several studies have observed a twofold increase in exposure to respirable particles can cause an increase in lung cancer of 30\%-50\% (Cohen and Pope, 1995; Sonwani and Kulshrestha, 2018; Bai et al., 2020). Air pollution is also linked to heart disease, stroke, and chronic obstructive pulmonary disease. During 2010 to 2020, studies have revealed significant associations between exposure to airborne air pollutants and premature mortality risk (Rajak and Chattopadhyay, 2019; Saxena and Srivastava, 2020). Navinya et al. (2020) compared the concentrations of criteria pollutants during the nationwide lockdown between 17 cities across India. They noted that, among the criteria air pollutants, $\mathrm{PM}_{2.5}$ and $\mathrm{PM}_{10}$ concentrations exhibited the largest declines, with significant reductions in the cities in the Indo-Gangetic plains (Navinya et al., 2020). Fine particulate matter $\left(\mathrm{PM}_{2.5}\right)$ is estimated to be associated with 2.9 million premature deaths worldwide (Stanaway et al., 2018; Saxena and Sonwani, 2019). India has a particularly high burden of disease and mortality due to air pollution, with most cases reported in North India (Balakrishnan et al., 2019), which is known to have poor air quality (Saxena et al., 2020).

Several studies have assessed the impact of lockdown on air quality in India, with a main focus on metro areas (Jain and Sharma, 2020). However, no study has evaluated the impact of COVID19 lockdown on respirable particles in North India or explored the health benefits. Therefore, the aim of the present study was to quantify the health benefit due to lockdown in India. In particular, we assessed particle deposition in the tracheobronchial region of human lungs and mortality before lockdown and during the lockdown phases. Assessments were based on the temporal variations in $\mathrm{PM}_{2.5}$ concentrations in four nonattainment cities (NACs) of Uttar Pradesh and the Delhi-National Capital Region (NCR).

\section{METHODS}

In the present study, we observed for variations in respirable particle concentrations and then evaluated the associated health benefits by calculating mortality during COVID-19 lockdown in various cities in North India-given the implications of the relevant results to health and pollution mitigation strategies in the near future.

\subsection{Study Area}

Four NACs in Uttar Pradesh, namely Agra, Kanpur, Lucknow, and Varanasi, and the Delhi-NCR region (including Delhi, Ghaziabad, and Noida) were analyzed in this study (Fig. 1). The Delhi-NCR, a large region surrounding the national capital, is one of the largest megacities in India. This 


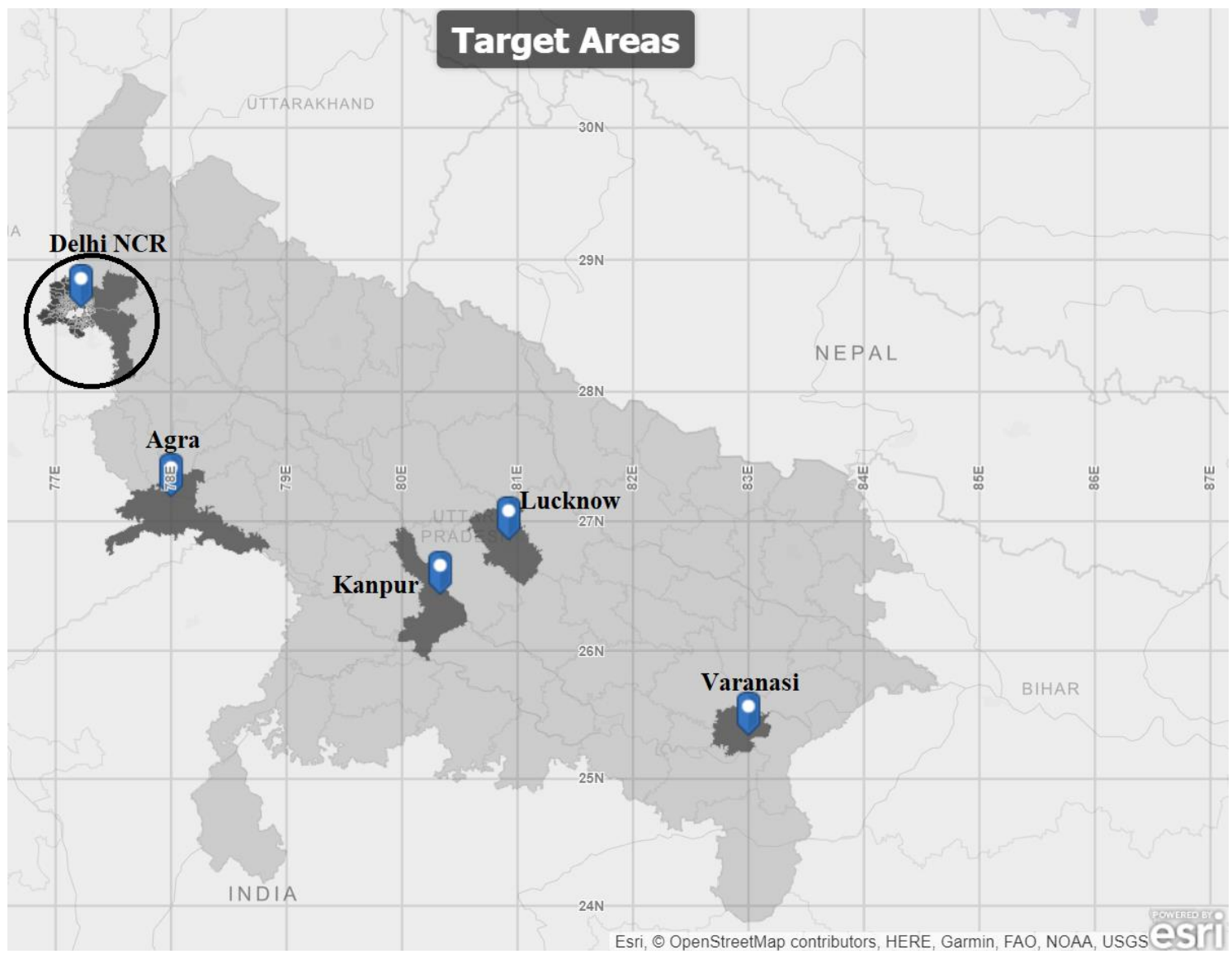

Fig. 1. Map of Delhi and the cities in Uttar Pradesh investigated in this study (Dark grey circle encompasses the NCR, dark grey areas represent selected city district, and light grey is the state of Uttar Pradesh).

region has highest number of registered vehicles in India and faces severe air quality problems (Srivastava et al., 2008). The other four NACs cover the area of Uttar Pradesh and vary substantially in terms of size and type. Uttar Pradesh is one of the most densely populated states in India, and it has approximately $10.4 \%$ of the total vehicles registered in India (MORTH, 2017). Lucknow is a large metropolitan city and the capital of Uttar Pradesh, Kanpur is an industrial and academic hub, Agra is home to the world-famous Taj Mahal, and Varanasi has religious and spiritual importance. The population distributions of the seven studied cities differ substantially. In this study, the cities with the highest and lowest populations were Delhi and Noida, respectively. Due to its limited land area, Agra has the highest population density, followed by Delhi and Varanasi. The NCR cities of Ghaziabad and Noida have the lowest population densities in the present study (Fig. 8).

The selected study sites in Uttar Pradesh contribute $2.2 \%$ of the total registered vehicles in India (Lucknow, 0.8\% [1,978,345]; Kanpur, 0.6\% [1,632,682]; Agra, 0.4\% [961,621]; Ghaziabad, $\sim 0.4 \%[917,600]$; and Varanasi, $\sim 0.4 \%[906,833])$.

Health benefits were quantified based on reductions in particle deposition in the tracheobronchial region and mortality decline among adults (age $>30$ years) during the lockdown.

\subsection{Lockdown Phases}

Observations were recorded between 1 March and 31 May, 2019, and the same period in 2020 (lockdown). The overall period was divided into five phases, starting from Phase 0 (prelockdown), followed by Phases 1-4, as per the lockdown phases implemented by the Government of India. Table 1 briefly lists the durations and restrictions imposed during each phase. During Phase 3, cities were classified into Red, Orange, and Green according to the prevalence of COVID-19 cases. Some rules were relaxed in the Green and Orange zones, but restrictions similar to Phase 1 were retained in the Red zones. All the sites in the present study were Red zones. Additional details about the lockdown phases are listed in Table S1. 
Table 1. Timeline of COVID-19 lockdown phases in India.

\begin{tabular}{|c|c|c|}
\hline Phase name & Dates & Major restriction or relaxations \\
\hline Phase 0 (Prelockdown) & 1-24 March 2020 (24 days) & No restriction; all activities in business-as-usual mode \\
\hline Phase 1 & 25 March-14 April 2020 (21 days) & $\begin{array}{l}\text { All transport, industrial establishment, commercial and } \\
\text { private establishments, and hospitality services closed }\end{array}$ \\
\hline Phase 2 & 15 April-3 May 2020 (19 days) & $\begin{array}{l}\text { Allowed: Farming operation, some industries, movement of } \\
\text { cargo }\end{array}$ \\
\hline Phase 3 & 4-17 May 2020 (14 days) & $\begin{array}{l}\text { Cities are classified into three zones (Red, Orange, and } \\
\text { Green). Relaxation of rules in the Green and Orange zones. } \\
\text { Allowed: Activities permitted during Phase } 2 \text { and } \\
\text { construction activities and movement of vehicles for } \\
\text { selected activities permitted. } \\
\text { Restrictions similar to Phase } 1 \text { applied in the Red zones }\end{array}$ \\
\hline Phase 4 & 18-31 May 2020 (14 days) & $\begin{array}{l}\text { Allowed: Movement of vehicles without any special } \\
\text { conditions along with the opening of the industry. }\end{array}$ \\
\hline
\end{tabular}

\subsection{Particulate Matter Data Collection}

Continuous ambient air quality data, meteorological data, and secondary data were collected from the Central Pollution Control Board (CPCB) of New Delhi (CPCB, 2020); these data included the concentrations of particulate matter with a diameter of $\leq 2.5 \mu \mathrm{m}\left(\mathrm{PM}_{2.5}\right.$; unit: $\mu \mathrm{g} \mathrm{m}^{-3}$; Indian Air Quality Standard: $60 \mathrm{\mu g} \mathrm{m}^{-3}$ ). We collected continuous 24-hour averaged data not only for the 91 days over all the lockdown phases in 2020 but also for 2019 to enable comparison. Table S2 lists the air quality monitoring stations included in this study, with details about the number of data points per city and the sampling station details.

\subsection{Data Analysis}

Changes in $\mathrm{PM}_{2.5}$ concentrations in NACs due to restrictions during lockdown were examined for two periods by using time series plots. $\mathrm{PM}_{2.5}$ concentrations were plotted for 2020 and 2019 (without lockdown measures), and differences between the 2 years were examined. Furthermore, trends in particle concentrations over the lockdown phases were assessed. For Delhi and Lucknow, which have multiple air quality monitoring stations, the collected variables from the different stations were averaged. Paired $t$ tests were conducted to test for significant differences in particle concentrations between the lockdown phases in 2020 and the 2019 baseline.

\subsection{Health Benefit Quantification}

The decline in natural deaths per 100,000 persons due to a reduction in air pollution was modeled using AirQ+. In this model, the receptor is an individual living in the city who is exposed to the ambient environment. The highest exposure is likely to be observed in a person who stands by the sidewalk for the whole day (e.g., a traffic policeman). The model yields predictions for this worst-case scenario (assuming that pollutant concentrations are higher outdoors than indoors). The mass of respirable particles deposited in the tracheobronchial region was calculated based on the particulate concentrations at selected sites over a 24-h period using the multiple-path particle dosimetry (MPPD) model. The calculations for the lockdown period were compared with those of the prelockdown period (Phase 0: 1-24 March 2020). The percent change, which was attributed primarily due to the reduction in respirable particulates in the ambient air during lockdown, is referred to as the health benefit herein. The AirQ+ and MPPD models are described briefly as follows:

\subsection{AirQ+}

The change in mortality attributable to particle inhalation was estimated using the AirQ+ model. This model was developed by the Regional Office for Europe of the WHO (WHO, 2016). In this model, at-risk population is defined adults aged $>30$ years, and the incidence rate is calculated as the number of new disease cases divided by the number of at-risk persons. We calculated the change in incidence with respect to the pre-lockdown period. To calculate the decline in mortality, the short-term effect of $\mathrm{PM}_{2.5}$ was considered. The average values of respirable particulates for 
the respective cities were recorded at the real-time monitoring stations of the CPCB (Fig. 3). The total population, at-risk population, incidence rate, and area of the seven studied cities were obtained from the official census by the Government of India in 2011 (Fig. 8) (Census of India Website : Office of the Registrar General \& Census Commissioner, India, 2011).

\subsection{MPPD}

The percent change in the mass of respirable particulates deposited in the human respiratory system across various regions was calculated using the Eulerian MPPD model (version 3.04). This model was developed by the Chemical Industry Institute of Toxicology and the Dutch National Institute for Public Health and the Environment. The respiratory tract is divided into three parts: the head, tracheobronchial region, and pulmonary region. The head comprises the nose, mouth, and upper trachea region and accounts for almost all (99.61\%) areas of respirable particulate deposition. In the lungs, the tracheobronchial region consists of the lower trachea and bronchi (branch-like airways), whereas the pulmonary region consists of the alveoli. Particle deposition is approximately three times higher in the tracheobronchial region than in the pulmonary region; thus the tracheobronchial region was investigated in this study.

To calculate particle deposition in the tracheobronchial region, we adopted the human YehSchum Single Path symmetric lung model. An individual standing on a sidewalk for 8 hours was considered for the exposure scenario. The default parameters for the model are an adult man at rest (i.e., upright body orientation, respiratory frequency of 12 breaths $\mathrm{min}^{-1}$, functional reserve capacity [FRC] of $3300 \mathrm{~mL}$, upper respiratory tract [URT] volume of $50 \mathrm{~mL}$ at a fixed tidal volume of $625 \mathrm{~mL}$, inspiratory fraction of 0.5 , and nasal route breathing). The model was applied to respirable particulates with a density of $1.4 \mathrm{~g} \mathrm{~cm}^{-3}$, and a geometric standard deviation (GSD) of 3.00 was assumed.

\section{RESULTS AND DISCUSSION}

Spatiotemporal variations in particle concentrations are presented as the observed particle concentrations during the study period, the trends observed in particle distribution across the lockdown phases, and the health benefits due to variations in respirable particulates.

\subsection{Spatiotemporal Trends in Particle Concentrations during the 2020 Lockdown Period}

Fig. 2 shows the average $\mathrm{PM}_{2.5}$ concentrations during the lockdown phases of 2020 for the selected cities. During prelockdown (Phase 0 ), the average daily $\mathrm{PM}_{2.5}$ concentration varied between 55 and $80 \mu \mathrm{g} \mathrm{m}^{-3}$. Five of the cities had ambient $\mathrm{PM}_{2.5}$ concentrations higher than the prescribed 24-hour average limit in India of $60 \mu \mathrm{g} \mathrm{m}^{-3}$. Toward the end of the lockdown period (i.e., during Phase 4), the ambient levels in Lucknow and cities in the NCR again exceeded the permissible standard. During Phase 1 , a significant decrease $(p<0.01)$ in particle concentrations was observed. Delhi exhibited a consistent increase in ambient levels after lockdown Phase 1. Table 2 lists the average concentrations of the respirable particles during the lockdown phases of 2020 and for the 2019 baseline.

During Phase 0 , no restrictions were enforced by the Indian government; therefore, the ambient particulate concentrations represented normal conditions. The mass concentrations for each phase were normalized with respect to Phase 0 for the studied cities. This enabled the impact of lockdown restrictions on respirable particulate concentrations to be quantified. Moreover, we calculated the ratio $\mathrm{P}_{\mathrm{x}} / \mathrm{P}_{0}$, where $\mathrm{P}_{\mathrm{x}}$ represents the mean $\mathrm{PM}_{2.5}$ concentration during phase $\mathrm{x}(\mathrm{x}=$ $1,2,3$, or 4$)$, and $P_{0}$ is the mean $P_{2.5}$ concentration during Phase 0 . For the studied cities, Fig. 3 shows $P_{x} / P_{0}$ (the average normalized phasewise $P_{2.5}$ ratios). $P_{x} / P_{0}>1$ represents an increase in the concentration of respirable particles with respect to Phase 0 . For all the selected cities, we observed $\mathrm{P}_{\mathrm{x}} / \mathrm{P}_{0}<1$ for Phases $1-3$. This indicated that, in terms of respirable particulates, the ambient air quality was better during the first three phases of lockdown than during Phase 0 . The reduction in particle concentrations was a result of the restrictions imposed by the Government of India, which were subsequently relaxed during Phase 4 (Table S1). 


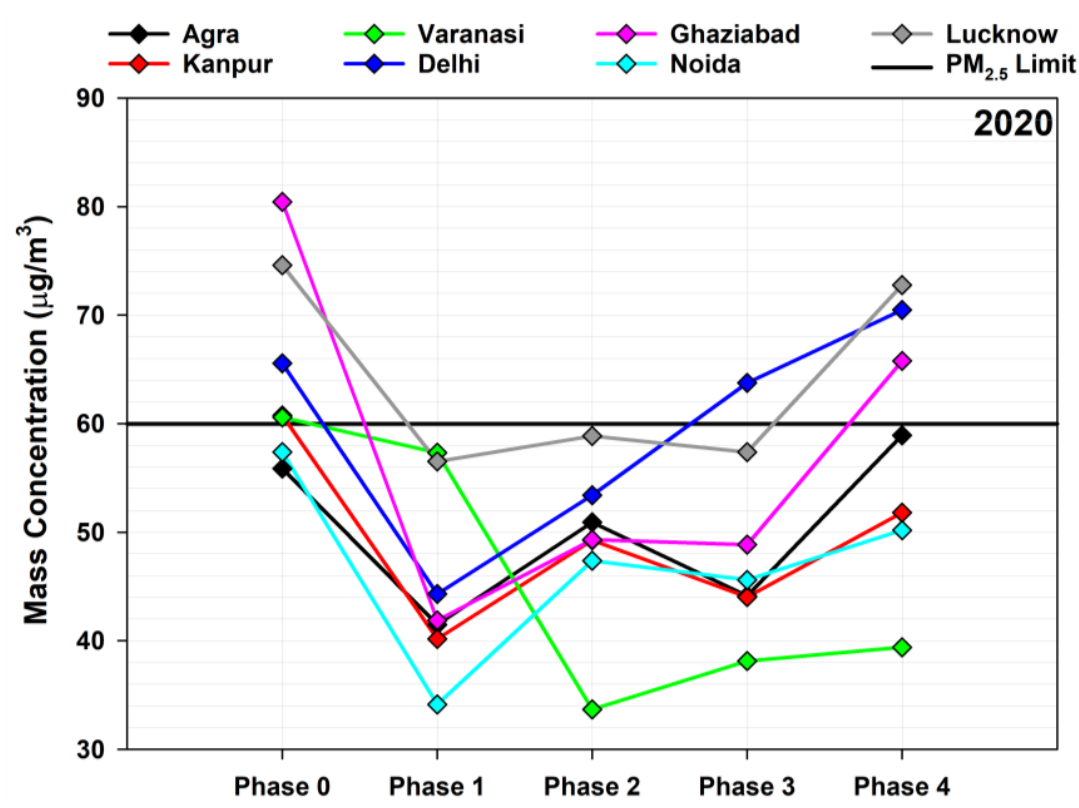

Fig. 2. Average $\mathrm{PM}_{2.5}$ mass concentrations during different lockdown phases in different cities in 2020.

Table 2. Average $P M_{2.5}$ mass concentration (means \pm standard deviations, unit: $\mu \mathrm{g} \mathrm{m}^{-3}$ ) for the studied cities.

\begin{tabular}{lllllll}
\hline & & Phase 0 & Phase 1 & Phase 2 & Phase 3 & Phase 4 \\
\hline Agra & 2019 & $\mathbf{7 5 . 1 8} \pm \mathbf{1 8 . 8 8}$ & $\mathbf{7 5 . 8 8} \pm \mathbf{1 6 . 1 9}$ & $\mathbf{6 9 . 0 4} \pm \mathbf{1 9 . 1 9}$ & $\mathbf{7 6 . 1 9} \pm \mathbf{2 7 . 7 5}$ & $53.87 \pm 11.82$ \\
& 2020 & $\mathbf{5 5 . 8 8} \pm \mathbf{1 6 . 7 8}$ & $\mathbf{4 1 . 4 9} \pm \mathbf{1 4 . 5 7}$ & $\mathbf{5 0 . 9 1 \pm 1 4 . 3 7}$ & $\mathbf{4 4 . 1 3} \pm \mathbf{1 0 . 9 7}$ & $58.95 \pm 15.82$ \\
Kanpur & 2019 & $64.81 \pm 19.86$ & $\mathbf{6 9 . 9 4} \pm \mathbf{2 3 . 4}$ & $\mathbf{6 3 . 0 3} \pm \mathbf{1 8 . 2 3}$ & $\mathbf{6 8 . 5 4} \pm \mathbf{1 8 . 4}$ & $61.34 \pm 16.01$ \\
& 2020 & $60.78 \pm 19.76$ & $\mathbf{4 0 . 1 8} \pm \mathbf{1 3 . 2 2}$ & $\mathbf{4 9 . 2 6} \pm \mathbf{2 4 . 6 4}$ & $\mathbf{4 4 . 0 4} \pm \mathbf{1 4 . 2 2}$ & $51.79 \pm 12.53$ \\
Varanasi & 2019 & $\mathbf{1 1 2 . 0 2} \pm \mathbf{4 0 . 4 6}$ & $\mathbf{9 7 . 7 4} \pm \mathbf{2 7 . 6 5}$ & $\mathbf{9 6 . 9 7} \pm \mathbf{2 3 . 4 5}$ & $\mathbf{9 4 . 3} \pm \mathbf{1 5 . 4 9}$ & $\mathbf{9 1 . 1 5} \pm \mathbf{2 6 . 3 8}$ \\
& 2020 & $\mathbf{6 0 . 5 9} \pm \mathbf{2 7 . 1 9}$ & $\mathbf{5 7 . 3 3} \pm \mathbf{1 7 . 9 6}$ & $\mathbf{3 3 . 6 7} \pm \mathbf{1 2 . 1 3}$ & $\mathbf{3 8 . 1 3} \pm \mathbf{1 3 . 6 5}$ & $\mathbf{3 9 . 4 1} \pm \mathbf{1 4 . 5 6}$ \\
Lucknow & 2019 & $\mathbf{9 9 . 1 9} \pm \mathbf{2 0 . 6 6}$ & $\mathbf{1 1 1 . 1 9} \pm \mathbf{2 8 . 9 9}$ & $\mathbf{1 0 5 . 4 1} \pm \mathbf{3 8 . 2 7}$ & $\mathbf{8 0 . 8} \pm \mathbf{1 4 . 5 8}$ & $84.93 \pm 14.3$ \\
& 2020 & $\mathbf{7 4 . 6 2} \pm \mathbf{2 4 . 9 4}$ & $\mathbf{5 6 . 5 2} \pm \mathbf{1 6 . 8 3}$ & $\mathbf{5 8 . 8 7} \pm \mathbf{1 9 . 7 5}$ & $\mathbf{5 7 . 3 8} \pm \mathbf{1 6 . 6 4}$ & $\mathbf{7 2 . 7 8} \pm 24.22$ \\
Ghaziabad & 2019 & $92.48 \pm 25.75$ & $\mathbf{1 0 7 . 2 8} \pm \mathbf{3 8 . 5 8}$ & $\mathbf{8 2 . 6 8} \pm \mathbf{3 0 . 3 1}$ & $\mathbf{1 1 8 . 8 2} \pm \mathbf{4 5 . 5}$ & $\mathbf{8 2 . 7 3} \pm \mathbf{2 4 . 5 1}$ \\
& 2020 & $80.44 \pm 32.44$ & $\mathbf{4 1 . 8 7} \pm \mathbf{2 1 . 0 6}$ & $\mathbf{4 9 . 3 1} \pm \mathbf{2 0 . 0 5}$ & $\mathbf{4 8 . 8 5} \pm \mathbf{1 2 . 0 7}$ & $\mathbf{6 5 . 7 8} \pm \mathbf{3 0 . 3 6}$ \\
Noida & 2019 & $\mathbf{8 8 . 4 6} \pm \mathbf{2 5 . 3 2}$ & $\mathbf{9 5 . 2} \pm \mathbf{3 3 . 0 7}$ & $\mathbf{6 5 . 4 8} \pm \mathbf{2 3 . 9 8}$ & $\mathbf{1 0 6 . 1 8} \pm \mathbf{3 2 . 2 7}$ & $\mathbf{6 6 . 2 8} \pm \mathbf{2 6 . 3 9}$ \\
& 2020 & $\mathbf{5 7 . 3 8} \pm \mathbf{2 2 . 0 2}$ & $\mathbf{3 4 . 1 4} \pm \mathbf{1 3 . 3 1}$ & $\mathbf{4 7 . 3 7} \pm \mathbf{2 4 . 9 2}$ & $\mathbf{4 5 . 6 1} \pm \mathbf{1 4 . 8 5}$ & $\mathbf{5 0 . 1 9} \pm \mathbf{2 5 . 9 2}$ \\
Delhi & 2019 & $\mathbf{8 6 . 7} \pm \mathbf{2 1 . 5 1}$ & $\mathbf{8 9 . 4 8} \pm \mathbf{2 7 . 9 2}$ & $\mathbf{7 7 . 4 1} \pm \mathbf{1 8 . 7 3}$ & $\mathbf{1 0 3 . 0 4} \pm \mathbf{3 4 . 0 3}$ & $66.88 \pm 15.86$ \\
& 2020 & $\mathbf{6 5 . 5 7} \pm \mathbf{2 1 . 6 7}$ & $\mathbf{4 4 . 3} \pm \mathbf{1 4 . 5 7}$ & $\mathbf{5 3 . 4 1} \pm \mathbf{1 8 . 4}$ & $\mathbf{6 3 . 7 7} \pm \mathbf{2 7 . 9 9}$ & $70.49 \pm 39.53$ \\
\hline
\end{tabular}

Bold values indicate significant differences $(p<0.01)$.

Bold italic values indicate significant differences $(p<0.05)$.

In all cities except for Varanasi, the maximum decline in $\mathrm{PM}_{2.5}$ concentrations was observed in Phase 1. During Phase 1 , the $P_{x} / P_{0}$ ratio was between 0.53 and 0.95 for all cities. Due to some relaxations in restrictions during Phase 2 , the pollutant concentrations increased in all cities, but $\mathrm{P}_{\mathrm{x}} / \mathrm{P}_{0}$ ratio remained $<1$. However, Varanasi exhibited a substantial decline even during Phase 2. In Phase 3, Indian cities were classified into three zones (Table S1) according to positive COVID-19 case prevalence.

Relaxations were implemented in the Orange and Green zones. All the cities in the present study were classified as Red zones, and their lockdown restrictions in Phase 3 were similar to those of Phase 1.

The particle concentrations were consequently lower in Phase 3 than in Phase 2 for all cities except Delhi and Varanasi. Moreover, for all cities, the particle concentration was higher in Phase 4 than in Phase 3. The $\mathrm{PM}_{2.5}$ concentration increased by 3\%-35\% from Phase 3 in the studied cities, with substantial increases for Agra, Lucknow, and Ghaziabad and the minimum change for Varanasi. 


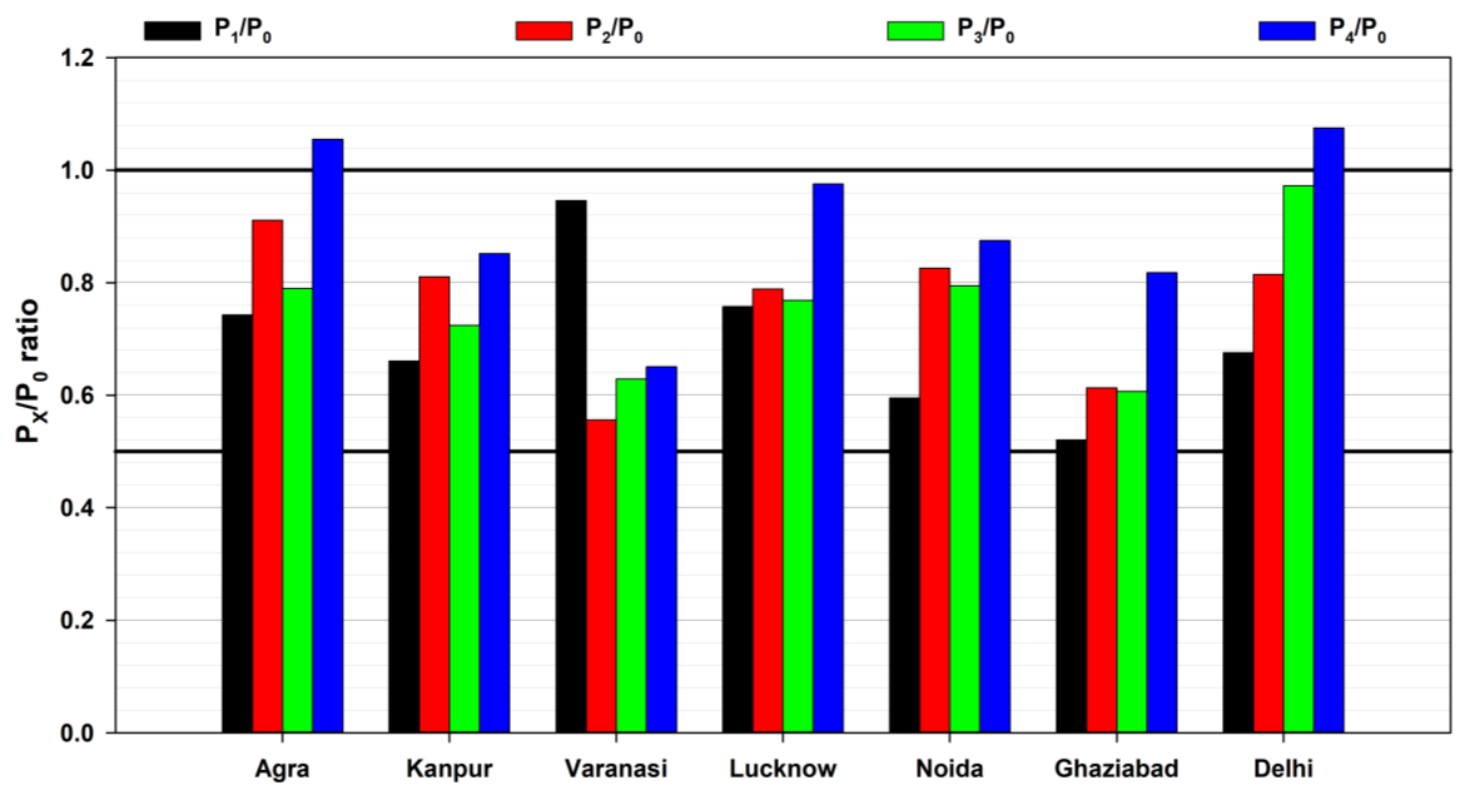

Fig. 3. $P M_{2.5}$ mass concentrations during different lockdown phases normalized to pre-lockdown levels $\left(P_{x} / P_{0}\right)$.

Relaxations in restrictions on travel and industrial activities was the major factor contributing toward higher $\mathrm{PM}_{2.5}$ concentration in Phase 4. Moreover, among the meteorological parameters presented in Table S3, relative humidity $(\mathrm{RH})$ was the only parameter exhibiting an increase from 2019 to 2020. This indicates that PM formation under the influence of high RH may result in the formation of secondary aerosol based on precursors released from different sources (Cheng et al., 2015; Sonwani and Kulshrestha, 2019).

Further investigation revealed that pollutant concentrations in Delhi increased through each lockdown phase; the average $\mathrm{PM}_{2.5}$ concentration was higher during the final phase of lockdown $\left(\mathrm{PM}_{2.5}\right.$ avg $\left.=70.49 \pm 39.53 \mu \mathrm{g} \mathrm{m}^{-3}\right)$ than during the prelockdown period $\left(\mathrm{PM}_{2.5}\right.$ avg $=65.57 \pm 21.67$ $\mu \mathrm{g} \mathrm{m}^{-3}$ ). A similar trend was observed in Rio De Janeiro, Brazil; compared with the prelockdown period, Dantas et al. (2020) reported a 17\%-34\% decline in $\mathrm{PM}_{10}$ concentration in the first lockdown week. The PM 10 concentration then increased during the second and third weeks of lockdown. The authors attributed this increase to the lack of consensus regarding lockdown guidelines. This lack of consensus caused an influx of vehicles and people in the city, which resulted in a notable increase in $\mathrm{PM}_{10}$ concentration.

\subsection{Reduction in $\mathrm{PM}_{2.5}$ Mass Concentration from 2019 to 2020}

Figs. 4(a) and 4(b) show the daily variations of $\mathrm{PM}_{2.5}$ concentrations of the studied cities from 1 March to 31 May 2019 and from 1 March to 31 May 2020. The blue and orange lines represent $\mathrm{PM}_{2.5}$ concentrations during 2019 and 2020, respectively, and the yellow line represents the 24-hour National Ambient Air Quality Standards (NAAQS) (i.e., $60 \mu \mathrm{g} \mathrm{m}^{-3}$ ). The vertical lines represents the phases of lockdown, starting with Phase 0 (prelockdown). Notably, data from 2019 (base year without lockdown) are presented in phasewise manner for comparison with 2020. Table 2 lists the average concentrations of $\mathrm{PM}_{2.5}$ for each phase in 2019 and 2020. The phases with significant differences in $\mathrm{PM}_{2.5}$ concentration between 2019 and 2020 are highlighted in the table. During Phase 0, PM2.5 concentration was significantly lower in 2020 than in 2019 except for in Kanpur and Ghaziabad. Although PM2.5 concentration in 2020 was also lower in these two cities, the difference was nonsignificant $(p>0.01)$.

According to the time series plots in Fig. 4, for Phases 1-3, the concentrations of respirable particles were significantly lower in 2020 than in 2019 for all cities because of the imposition of lockdown. During Phase 4, the concentration returned to a level similar to that of 2019 in many of the cities.

Fig. 5 shows the percent change in average $\mathrm{PM}_{2.5}$ concentrations for 2020 relative to 2019. These values were calculated using the equation percent change $=\left[\left(C_{20}-C_{19}\right) \times 100 / C_{19}\right]$, where 


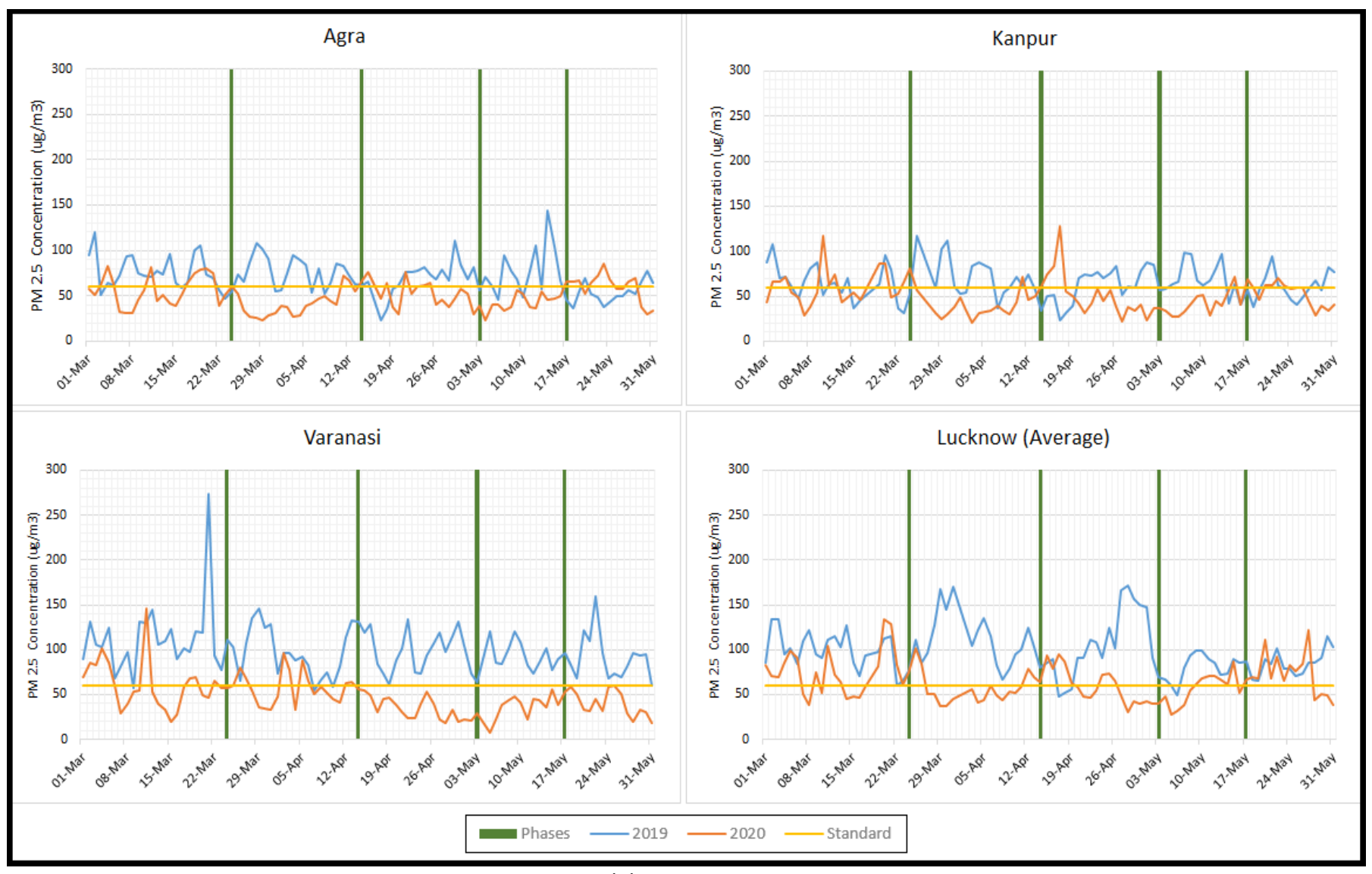

(a) Cities in UP
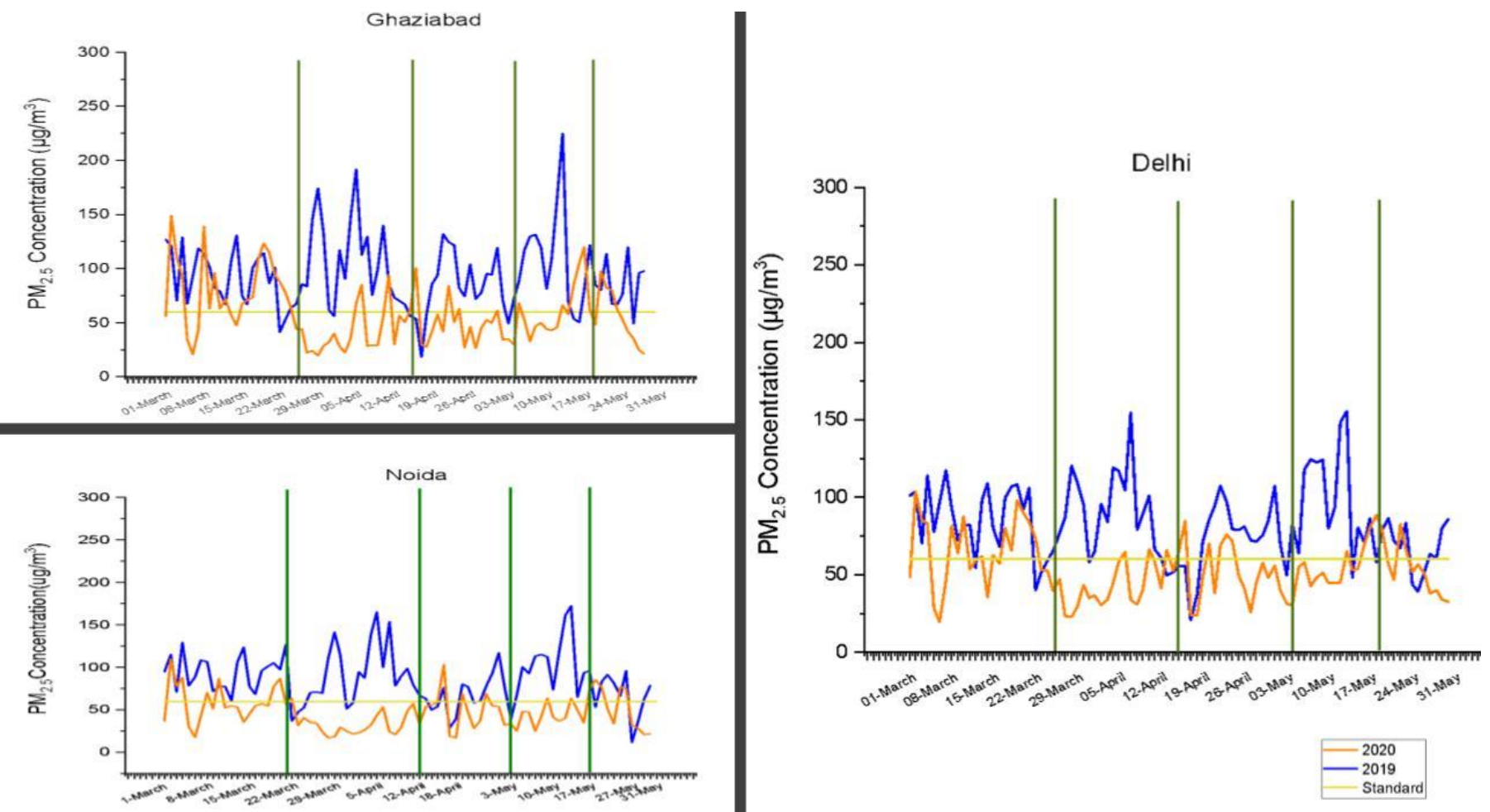

(b) Delhi-NCR

Fig. 4. Time series plots of 24-hour daily $\mathrm{PM}_{2.5}$ concentrations in (a) the four NACs of Uttar Pradesh and (b) the three cities in the Delhi-NCR for 2019 and 2020. Green vertical lines represent the phases of lockdown. 


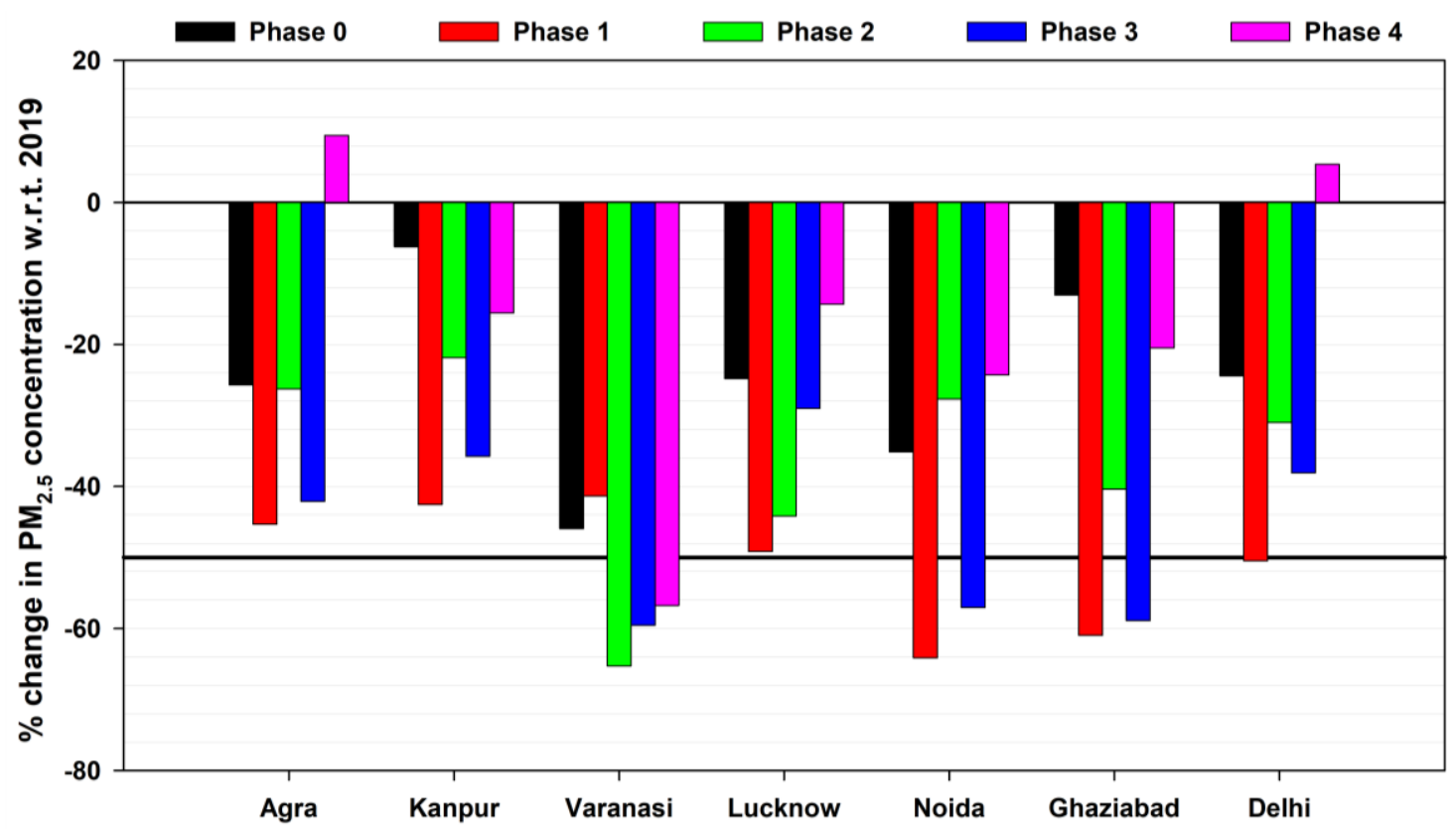

Fig. 5. Bar chart showing the percentage reduction of $P_{2.5}$ mass concentration in the year 2020 with respect to the year 2019 .

$\mathrm{C}_{19}$ and $\mathrm{C}_{20}$ are the concentrations of $\mathrm{PM}_{2.5}$ during 2019 and 2020, respectively. Overall, a decline in $\mathrm{PM}_{2.5}$ concentration was observed in 2020 from 2019 during all phases. However, this result did not hold during Phase 4 in Agra and Delhi. The greatest decrease in particle concentrations was observed in Phase 1 (red bar), followed by Phase 3 (blue bar), for all cities except Varanasi. During Phase 1, the average decline in $\mathrm{PM}_{2.5}$ from 2019 was $>40 \%$ in all cities. Similar reductions in $\mathrm{PM}_{2.5}$ of $40 \%-60 \%$ have been noted for other Indian cities during the same period (Kumar et al., 2020; Navinya et al., 2020; Singh et al., 2020). During Phase 4, all cities expect for Varanasi exhibited their minimum percent change with respect to 2019. However, for Delhi and Agra, the $\mathrm{PM}_{2.5}$ concentrations in Phase 4 were higher than in 2019 (positive value of the pink bar in Fig. 5). This result was attributed to relaxations of the regulations on travel, industrial activity, and human gatherings during this phase.

Varanasi exhibited a distinct trend from the other cities. A very steep decline (>40\%) in the concentration of $\mathrm{PM}_{2.5}$ was observed in 2020 relative to that in 2019 for all lockdown phases. This trend was attributable to the severe restriction on religious ceremonies (e.g., Aarti) on the ghats of the Ganges River during all lockdown phases. Varanasi is a major spiritual center in India; the normal influx of tourists was almost entirely stopped during 2020 due to strict travel restrictions, further reducing the particulate concentrations.

In the cities of Enshi, Jingmen, and Wuhan in central China, $\mathrm{PM}_{2.5}$ and $\mathrm{PM}_{10}$ concentrations decreased by an average of 30\%-40\% during their lockdown period (January-March 2020) compared with the average concentrations during the same period from 2017 to 2019 (Xu et al., 2020). Similar observations were reported from India by Navinya et al. (2020), who compared air quality in 17 Indian cities. Their study reported that among all air pollutants, $\mathrm{PM}_{2.5}$ and $\mathrm{PM}_{10}$ concentrations declined the most, particularly in North Indian cities in the Indo-Gangetic plains. Their results revealed an average reduction of $52.3 \%$ in $\mathrm{PM}_{2.5}$ in Phase 1 relative to 2019 for five North Indian cities. In particular, they noted decreases in Delhi, Ambala, Amritsar, Jaipur, and Lucknow of $58.1 \%, 37.1 \%, 64.5 \%, 50.5 \%$, and $51.5 \%$, respectively. These results were similar to those of the present study, which revealed average $44.6 \%$ and $58.5 \%$ reductions for the Uttar Pradesh cities and the Delhi-NCR region, respectively.

\subsection{Influence of Transportation Restrictions}

On closer inspection, the cities situated in the NCR (i.e., Delhi, Noida, and Ghaziabad) exhibited greater changes than the other four towns during Phase 1 (Fig. 4). Vehicular movement is significantly higher in the NCR region than in the other four NACs. According to the road transport 
yearbook (2016-2017) published by the Ministry of Road, Transport and Highways (MORTH) in September 2019, Delhi has the highest number of registered vehicles (> 10 million), followed by Lucknow and Kanpur, with a total of approximately 2 million registered vehicles in both cities combined. The number of registered vehicles in the other cities range of 0.9-1 million. In general, cities with a more vehicles exhibited a greater decline in $\mathrm{PM}_{2.5}$ concentrations in 2020 relative to 2019. The transportation sector, which is a significant contributor to particulate concentrations in all of these cities, was effectively terminated during lockdown, and similar observation were reported in other studies. In Milan, Italy, Collivignarelli et al. (2020) reported $37 \%-44 \%$ and approximately $47 \%$ declines in $\mathrm{PM}_{2.5}$ concentration during partial and total lockdown compared with that in the prelockdown period, respectively. Kerimray et al. (2020) reported an average decrease of approximately $21 \%(6 \%-34 \%)$ in Almaty, Kazakhstan. These studies have highlighted that reduction in transportation was a primary factor for the decline in particulate concentrations.

\subsection{Health Benefits Due to Variations in Respirable Particulate Concentrations}

The imposition of lockdown and the resulting cessation of vehicular movement (except for essential services) caused a sharp decrease in ambient respirable particulate concentrations. Health benefits due to the reduced exposure to respirable particles have been documented, because they are major carriers of toxins, bacteria, and fungi. Health impacts from particulate inhalation were quantified using the MPPD and AirQ+ models. These models were utilized to calculate health benefits due to the prevalence of cleaner air during the lockdown period. The MPPD results revealed a decrease in the percent deposition of fine particulate matter in the tracheobronchial region of the lungs. Moreover, the AirQ+ results indicated a decline in mortality due to the decrease in the concentrations of fine particles during lockdown. Calculations were performed for all phases of lockdown, and the results were compared with those of the prelockdown period.

\subsection{Reduced particle Deposition in the Tracheobronchial Region of the Lungs (MPPD)}

Fig. 6 shows the percent reduction of particle deposition in the tracheobronchial region of the lungs due to the inhalation of respirable particles during the lockdown. Fig. 6 reveals a reduction in particle deposition during each phase of lockdown for all the studied cities. Reductions during Phases 1 to 4 of lockdown were calculated based on deposition with the average concentrations of respirable particulates during Phase 0 (prelockdown) as the base value. Percent reduction were then calculated as $\left[\left(D_{p 0}-D_{p i}\right) \times 100 / D_{p 0}\right]$, where $D_{p 0}$ and $D_{p i}$ are the depositions in tracheobronchial region calculated based on the average concentration of $P M_{2.5}$ in Phase 0 and Phase $i(i=1,2,3$, or 4), respectively. As per this equation, the closer the average value in a phase was to the prelockdown concentration, the lower the reduction in particle deposition in the tracheobronchial region was.

Average respirable particulate concentrations only exceeded prelockdown concentrations during lockdown in Agra and Delhi (Phase 4) (Fig. 5; black red, blue, and magenta represent Phases 1, 2, 3, and 4, respectively). This increase in particle concentrations suggested that particle deposition may have increased.

Spatiotemporal variation was observed for the reduction in particle deposition. Only Delhi and Agra exhibited an increase in deposition during Phase 4. Lockdown restrictions were minimized in Phase 4 for other cities, thus enabling more movement of traffic within the cities. Except for Varanasi in Phase 1 and Agra and Delhi in Phases 3 and 4, the percent reduction in fine particle depositions followed a decreasing trend: Phase 1 (7\%-47\%), Phase 2 (7\%-44\%), Phase 3 (2\%$39 \%)$, and Phase $4(-8 \%$ to $36 \%)$. This trend matched the progressive relaxation of restrictions during the phases of lockdown. The increased concentration of respirable particles after Phase 1 (Fig. 4) resulted in an increased deposition in the tracheobronchial region.

All the cities except for Varanasi exhibited similar results; Phase 1 was the most effective for the reduction of tracheobronchial particle deposition compared with the prelockdown concentrations, and Phase 4 was the least effective. For Varanasi, Phase 2 was the most effective.

Varanasi was the city with the maximum difference in reduction in deposition in the tracheobronchial region between two consecutive phases: a 7\% reduction in Phase 1 as followed by a $44 \%$ reduction in Phase 2 . In the other six cities, vehicular emissions are the most important 


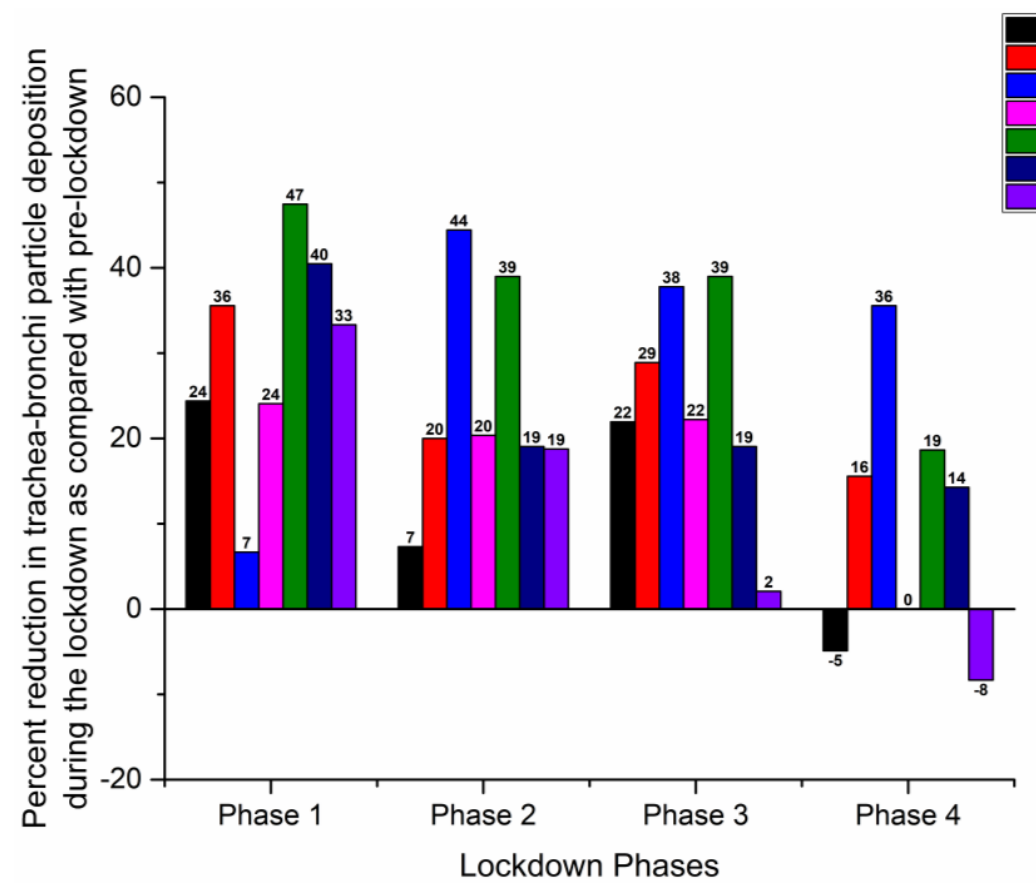

Fig. 6. Percent reduction in particle deposition in the tracheobronchial region during lockdown phases relative to the pre-lockdown period.

source of particle pollution; however, Varanasi has other prominent sources of respirable particles such as cremation rituals and Ghat pooja. Ritual ceremonies were banned in the city during Phase 2, resulting in a sharp decrease in particulate concentrations (Fig. 4) and a significant decline in particle deposition in the tracheobronchial region of the lungs. In terms of reduced respirable particulates deposition, Phase 1 and 2 were the least and most effective lockdowns, respectively, for Varanasi.

\subsection{Reduction in Mortality due to Lockdown (AirQ+)}

Fig. 7 shows the number of deaths prevented (per 100,000 persons, age $>30$ years) due to decreased air pollution during lockdown. We calculated deaths prevented based on the deaths during the prelockdown period of 2020 (Phase 0 ). Reduction in mortality was calculated as $\mathrm{M}_{\mathrm{p} 0}-$ $M_{p i}$, where $M_{p 0}$ and $M_{p i}$ are the numbers of deaths calculated using the average concentration of respirable particulates for Phase 0 and Phase $i(i=1,2,3$, or 4$)$, respectively. This method was adopted for all phases and for all cities.

According to Fig. 7, mortality prevention was maximized in all the cities except Varanasi during Phase 1, followed by Phases 3 and 2. As for particle deposition in the tracheobronchial region, the reduction of particulate concentrations reduced the number of mortalities. Hence, Phase 4 exhibited the least effective reduction in mortality. In Delhi and Agra, where respirable particulate concentrations were greater in Phase 4 than in Phase 0 , increases in mortality of 0.49 and 0.66 deaths per 100,000 persons were observed, respectively.

For all phases combined, the maximum reduction in mortality was observed in Ghaziabad. As many as 8.01 deaths per 100,000 persons were prevented in Ghaziabad during Phase 1. In Phase 2, Varanasi exhibited the largest mortality reduction. Mortality increased in Phase 4 for Delhi and Agra. In Varanasi, where the respirable particulate concentrations in Phase 1 were closest to those in Phase 0 (Fig. 3), the least reduction in mortality was observed during Phase 1 (Fig. 7). Similar reductions were observed for particle deposition in the tracheobronchial region (Fig. 6). For Varanasi, Phase 1 was least effective with a mortality reduction of only 0.68 deaths per 100,000 persons, whereas Phase 2 was the most effective, with a reduction of 7.2 deaths per 100,000 persons.

Figs. 6 and 7 show the significant contributions of ambient reduced $\mathrm{PM}_{2.5}$ to improved health; these findings were corroborated by an extensive European study quantifying the health benefits from reduced $\mathrm{PM}_{2.5}$ in 26 cities (Ballester et al., 2008). According to their study, if the annual mean 


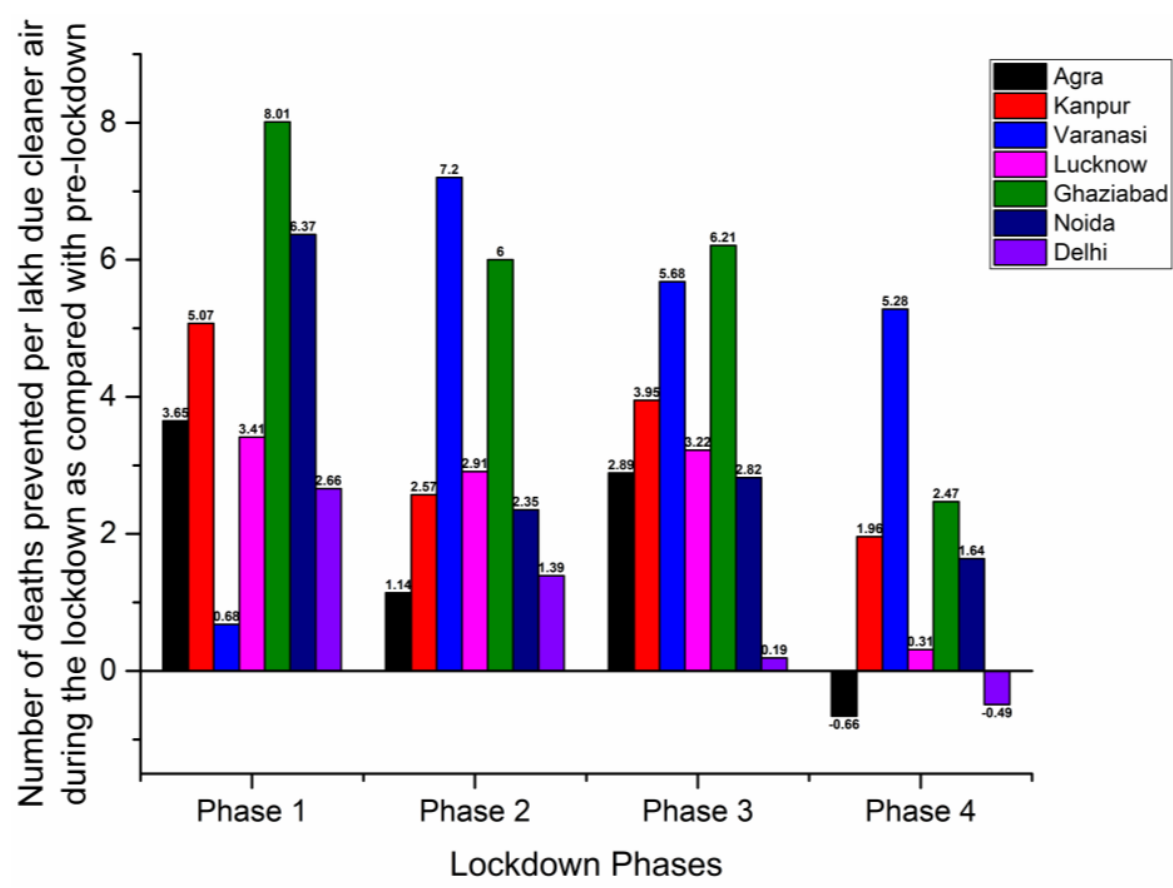

Fig. 7. Number of deaths prevented per 100,000 persons due to air pollution reduction during the phases of lockdown relative to the pre-lockdown period.

concentration of $\mathrm{PM}_{2.5}$ is reduced by $15 \mu \mathrm{g} \mathrm{m}^{-3}$, the total burden of mortality could be reduced among people aged $>30$ years. The percent reduction increased by seven times if $\mathrm{PM}_{2.5}$ concentrations were reduced to $10 \mathrm{\mu g} \mathrm{m}^{-3}$. Greenstone and Hanna (2014) examined the environmental regulations in India and found that air pollution regulations were associated with substantial improvements in air quality, resulting in a decrease in infant mortality of 0.64 deaths per 1000 live births.

\subsection{Air Quality Management in NACs}

The CPCB has identified 122 NACs with air pollutants $\left(\mathrm{PM}_{10}\right.$ and $\mathrm{PM}_{2.5}$ ) exceeding the NAAQS. After the identification of these cities, the National Clean Air Program (NCAP) was implemented; each state was asked to submit action plans to reduce air pollution concentrations by at least $20 \%$ by 2024 . NACs were requested to submit midterm 5-year action plans with 2019 as the base year. This plan may be extended up to 25 years after the midterm review. A main objective of the NCAP is the stringent implementation of mitigation measures for the prevention, control, and abatement of air pollution. This is a multisectoral collaborative approach that incorporates the Smart Cities framework All the cities in the present study, except Noida, are smart cities. Smart cities are defined as those that uses communication and information technologies to increase operational efficiency, share information, improve citizen welfare, and enhance the quality of government services. The relevance of the smart cities framework lies in the promotion of healthy cities. For instance, this framework can inform city residents about the current and forecasted air quality parameters, and they can take remedial actions accordingly (e.g., staying at home during days with high levels of pollution).

The analysis in the present study was a practical example of the health benefits of reducing air pollution. We observed that a maximum reduction in $\mathrm{PM}_{2.5}$ concentrations ( $>40 \%$ relative to 2019) in Phase 1 (Fig. 5) occurred in almost all cities, causing considerable reductions in mortality. The second highest reduction in particulate concentrations (> 30\%) was observed in Phase 3. Fig. 8 presents the population characteristics of the cities and populations. The details from Fig. 8 and the results of the health impact calculations are summarized in Table 3. City-specific results varied widely.

All cities except for Varanasi exhibited the cleanest air during Phase 1, along with their maximum reductions in mortality and particle deposition in the tracheobronchial region of the lungs (Delhi in Phase 4). For Varanasi, similar results were observed during Phase 2. 


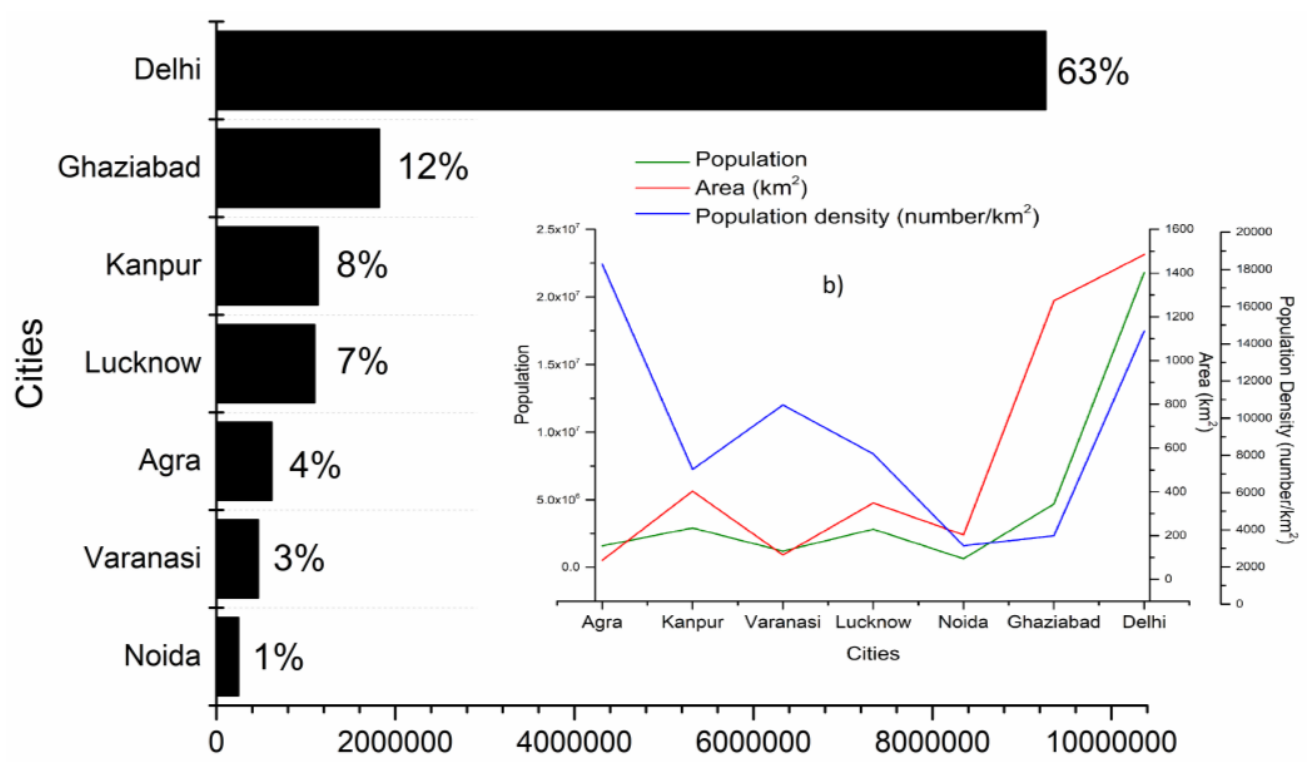

a) Risk population (age $>30$ years)

Fig. 8. (a) At-risk population in the seven studied cities arranged in decreasing order and (b) population distribution of the cities (Census of India Website: Office of the Registrar General \& Census Commissioner, India, 2011).

Table 3. Description of the highest and lowest of various parameters among the cities.

\begin{tabular}{|c|c|c|c|}
\hline Parameter & Level & City & Comment \\
\hline \multirow[t]{2}{*}{ Population density } & Highest & Agra, Delhi, Varanasi & \\
\hline & Lowest & Noida, Ghaziabad & \\
\hline \multirow{2}{*}{$\begin{array}{l}\text { Number of affected People } \\
\quad \text { (age }>30 \text { years) }\end{array}$} & Highest & Delhi & The lowest reduction in mortality per 100,000 persons \\
\hline & Lowest & Varanasi and Noida & The highest reduction in mortality per 100,000 persons \\
\hline \multirow{2}{*}{$\begin{array}{l}\text { Tracheobronchial deposition } \\
\text { reduction }\end{array}$} & Highest & Noida, Varanasi & \\
\hline & Lowest & No consistency & $\begin{array}{l}\text { The trend across the four phases: Varanasi, Agra, } \\
\text { Lucknow, Lucknow }\end{array}$ \\
\hline \multirow[t]{2}{*}{ Mortality reduction } & Highest & Ghaziabad & \\
\hline & Lowest & Delhi & \\
\hline
\end{tabular}

Varanasi and Noida exhibited the maximum reductions in mortality and particulate deposition, but these were also the lowest numbers of affected people. By contrast, Delhi had the highest number of affected people, with the second highest population density after Agra, and the lowest reduction in mortality. In Delhi, more deaths were reported during Phase 4 than during the prelockdown period, implying that Delhi was among the worst affected cities. In other words, the city with the highest affected population (i.e., Delhi) exhibited the least change in mortality between before and during the lockdown. By contrast, cities with low numbers of affected people (i.e., Noida and Varanasi) had the most significant health benefits.

In summary, Delhi and Noida had the highest and lowest number of affected people, respectively. Comparing these results with health parameters (i.e., tracheobronchial particulate deposition and mortality) indicated that the health parameters are independent of the size of the at-risk population. This observation has far-reaching implications for the NCAP clean air goals. The present findings suggest that a cost-benefit analysis should be conducted when aiming to improve air quality in NACs.

\section{CONCLUSIONS}

The results of the study are summarized as follows:

- We observed a significant improvement in PM$_{2.5}$ concentrations during the COVID-19 
lockdown, with the greatest change at the start of the lockdown in Phase 1. The Delhi-NCR exhibited a decline of approximately 58.5\% compared with 2019, and the four NACs of Uttar Pradesh exhibited an average reduction of $44.6 \%$.

- Health benefits were also highest during Phase 1. A reduction in mortality of 8.01 per 100,000 people was observed in Ghaziabad during Phase 1 compared with the prelockdown period.

- Compared with the prelockdown period (Phase 0), particulate deposition in the tracheobronchial region was reduced by an average of $30.14 \%$, with a corresponding mortality reduction of 29.85 per 100,000 persons.

Mortality and particulate deposition in the lungs are positively correlated with respirable particulate concentrations, which vary between cities. This suggests that even a small improvement in the concentration of respirable particulates leads to a considerable reduction in mortality. By contrast, a considerable decrease in respirable particulate concentrations in another city might result in only a small change in mortality.

In India, the COVID-19 lockdown provided unique natural experimental settings to assess the effects of air pollution and quantify the health benefits of a reduction in concentrations of respirable particulates. Although the reduction of pollutants during lockdown may not be practical in the long term, the results clearly show a significant improvement in health. These results may help policymakers and city planners to propose new approaches to control air pollution. Such approaches may be particularly useful in NACs, where concentrations of respirable particulates are very high. Strategies for pollution reduction should be city-specific. Additional studies on the costs incurred by implementing control strategies for reducing respirable particulate concentrations and the health benefits are also urgently needed.

\section{ACKNOWLEDGMENTS}

We are grateful to the Central Pollution Control Board for open access to the ambient air quality data used in the study. This manuscript was edited by Wallace Academic Editing. The support in English editing provided by Dr. M. Jain, SES, JNU, New Delhi, India is also acknowledged.

\section{DISCLAIMER}

The authors declare that they have no financial or personal interests that may influence the results presented in the manuscript.

\section{SUPPLEMENTARY MATERIAL}

Supplementary data associated with this article can be found in the online version at https://doi.org/10.4209/aaqr.200460

\section{REFERENCES}

Bai, L., Shin, S., Burnett, R.T., Kwong, J.C., Hystad, P., van Donkelaar, A., Goldberg, M.S., Lavigne, E., Weichenthal, S., Martin, R.V., Copes, R., Kopp, A., Chen, H. (2020). Exposure to ambient air pollution and the incidence of lung cancer and breast cancer in the Ontario Population Health and Environment Cohort. Int. J. Cancer 146, 2450-2459. https://doi.org/10.1002/ijc.32575

Balakrishnan, K., Dey, S., Gupta, T., Dhaliwal, R.S., Brauer, M., Cohen, A.J., Stanaway, J.D., Beig, G., Joshi, T.K., Aggarwal, A.N., Sabde, Y., Sadhu, H., Frostad, J., Causey, K., Godwin, W., Shukla, D.K., Kumar, G.A., Varghese, C.M., Muraleedharan, P., Agrawal, A., ... Dandona, L. (2019). The impact of air pollution on deaths, disease burden, and life expectancy across the states of India: The Global Burden of Disease Study 2017. Lancet Planet. Health 3, e26-e39. https://doi.org/1 0.1016/S2542-5196(18)30261-4

Ballester, F., Medina, S., Boldo, E., Goodman, P., Neuberger, M., Iñiguez, C., Künzli, N. (2008). Reducing ambient levels of fine particulates could substantially improve health: A mortality 
impact assessment for 26 European cities. J. Epidemiol. Community Health 62, 98-105. https://doi.org/10.1136/jech.2007.059857

Census of India Website: Office of the Registrar General \& Census Commissioner, India (2011). In Census India (Vol. 388, Issue 10053, pp. 1659-1724). https://censusindia.gov.in/ (accessed 10 June 2020).

Central Pollution Control Board (CPCB) (2020). https://cpcb.nic.in/ (accessed 5 June 2020).

Cheng, Y., He, K.B., Du, Z.Y., Zheng, M., Duan, F.K., Ma, Y.L. (2015). Humidity plays an important role in the $\mathrm{PM}_{2.5}$ pollution in Beijing. Environ. Pollut. 197, 68-75. https://doi.org/10.1016/j.en vpol.2014.11.028

Cohen, A.J., Pope, C.A. (1995). Lung cancer and air pollution. Environ. Health Perspect. 103, 219224. https://doi.org/10.1289/ehp.95103s8219

Collivignarelli, M.C., Abbà, A., Bertanza, G., Pedrazzani, R., Ricciardi, P., Carnevale Miino, M. (2020). Lockdown for CoViD-2019 in Milan: What are the effects on air quality? Sci. Total Environ. 732, 139280. https://doi.org/10.1016/j.scitotenv.2020.139280

Dantas, G., Siciliano, B., França, B.B., da Silva, C.M., Arbilla, G. (2020). The impact of COVID-19 partial lockdown on the air quality of the city of Rio de Janeiro, Brazil. Sci. Total Environ. 729, 139085. https://doi.org/10.1016/j.scitotenv.2020.139085

Greenstone, M., Hanna, R. (2014). Environmental regulations, air and water pollution, and infant mortality in India. Am. Econ. Rev. 104, 3038-3072. https://doi.org/10.1257/aer.104.10.3038

Jain, S., Sharma, T. (2020). Social and travel lockdown impact considering coronavirus disease (COVID-19) on air quality in megacities of india: Present benefits, future challenges and way forward. Aerosol Air Qual. Res. 20, 1222-1236. https://doi.org/10.4209/aaqr.2020.04.0171

Kanniah, K.D., Kamarul Zaman, N.A.F., Kaskaoutis, D.G., Latif, M.T. (2020). COVID-19's impact on the atmospheric environment in the Southeast Asia region. Sci. Total Environ. 736, 139658. https://doi.org/10.1016/j.scitotenv.2020.139658

Kerimray, A., Baimatova, N., Ibragimova, O.P., Bukenov, B., Kenessov, B., Plotitsyn, P., Karaca, F. (2020). Assessing air quality changes in large cities during COVID-19 lockdowns: The impacts of traffic-free urban conditions in Almaty, Kazakhstan. Sci. Total Environ. 730, 139179. https://doi.org/10.1016/j.scitotenv.2020.139179

Kumar, P., Hama, S., Omidvarborna, H., Sharma, A., Sahani, J., Abhijith, K.V., Debele, S.E., ZavalaReyes, J.C., Barwise, Y., Tiwari, A. (2020). Temporary reduction in fine particulate matter due to 'anthropogenic emissions switch-off' during COVID-19 lockdown in Indian cities. Sustainable Cities Soc. 62, 102382. https://doi.org/10.1016/j.scs.2020.102382

Mahato, S., Pal, S., Ghosh, K.G. (2020). Effect of lockdown amid COVID-19 pandemic on air quality of the megacity Delhi, India. Sci. Total Environ. 730, 139086. https://doi.org/10.1016/j.scitoten v.2020.139086

Metya, A., Dagupta, P., Halder, S., Chakraborty, S., Tiwari, Y.K. (2020). COVID-19 lockdowns improve air quality in the South-East Asian regions, as seen by the remote sensing satellites. Aerosol Air Qual. Res. 20, 1772-1782. https://doi.org/10.4209/aaqr.2020.07.0461

MORTH (2017). Road transport year book 2016-17, Published on Ministry of Road Transport \& Highways, Government of India. https://morth.nic.in/print/road-transport-year-books (accessed 02 June 2020).

Muhammad, S., Long, X., Salman, M. (2020). COVID-19 pandemic and environmental pollution: A blessing in disguise? Sci. Total Environ. 728, 138820. https://doi.org/10.1016/j.scitotenv.202 0.138820

Navinya, C., Patidar, G., Phuleria, H.C. (2020). Examining effects of the COVID-19 national lockdown on ambient air quality across urban india. Aerosol Air Qual. Res. 20, 1759-1771. https://doi.org/10.4209/aaqr.2020.05.0256

Rajak, R., Chattopadhyay, A. (2019). Short and long-term exposure to ambient air pollution and impact on health in India: A systematic review. Int. J. Environ. Health Res. 30, 593-617. https://doi.org/10.1080/09603123.2019.1612042

Ranjan, A.K., Patra, A.K., Gorai, A.K. (2020). Effect of lockdown due to SARS COVID-19 on aerosol optical depth (AOD) over urban and mining regions in India. Sci. Total Environ. 745, 141024. https://doi.org/10.1016/j.scitotenv.2020.141024

Saxena, P., Sonwani, S. (2019). Primary criteria air pollutants: environmental health effects. In Criteria Air Pollutants and their Impact on Environmental Health (pp. 49-82). Springer, Singapore. 
Saxena, P., Sonwani, S., Sharma, S.K., Kumar, P., Chandra, N. (2020). Carbonaceous aerosol variations in foggy days: A critical analysis during the fireworks festival. Fresenius Environ. Bull. 29, 6639-6656.

Saxena, P., Srivastava, A. (2020). Air Pollution and Environmental Health (Vol. 20). Springer Nature.

Singh, V., Singh, S., Biswal, A., Kesarkar, A.P., Mor, S., Ravindra, K. (2020). Diurnal and temporal changes in air pollution during COVID-19 strict lockdown over different regions of India. Environ. Pollut. 266, 115368. https://doi.org/10.1016/j.envpol.2020.115368

Sonwani, S., Kulshrestha, U. (2018). Morphology, elemental composition and source identification of airborne particles in Delhi, India. J. Ind. Geophys. Union 22, 607-620.

Srivastava, A., Gupta, S., Jain, V.K. (2008). Source apportionment of total suspended particulate matter in coarse and fine size ranges over Delhi. Aerosol Air Qual. Res. 8, 188-200. https://doi.org/10.4209/aaqr.2007.09.0040

Stanaway, J.D., Afshin, A., Gakidou, E., Lim, S.S., Abate, D., Abate, K.H., Abbafati, C., Abbasi, N., Abbastabar, H., Abd-Allah, F., Abdela, J., Abdelalim, A., Abdollahpour, I., Abdulkader, R.S., Abebe, M., Abebe, Z., Abera, S.F., Abil, O.Z., Abraha, H.N., Murray, C.J.L. (2018). Global, regional, and national comparative risk assessment of 84 behavioural, environmental and occupational, and metabolic risks or clusters of risks for 195 countries and territories, 19902017: A systematic analysis for the Global Burden of Disease Study 2017. Lancet 392, 19231994. https://doi.org/10.1016/S0140-6736(18)32225-6

Tobías, A., Carnerero, C., Reche, C., Massagué, J., Via, M., Minguillón, M.C., Alastuey, A., Querol, $X$. (2020). Changes in air quality during the lockdown in Barcelona (Spain) one month into the SARS-CoV-2 epidemic. Sci. Total Environ. 726, 138540. https://doi.org/10.1016/j.scitotenv.20 20.138540

World Health Organization (WHO) (2016). AirQ+: software tool for health risk assessment of air pollution. WHO Regional Office for Europe. https://www.euro.who.int/en/health-topics/envir onment-and-health/air-quality/activities/airq-software-tool-for-health-risk-assessment-of-airpollution (accessed 02 June 2020).

Worldometer (2020). Coronavirus: Cases and deaths. Worldometer. https://www.worldom eters.info/coronavirus/worldwide-graphs/ (accessed 1 June 2020).

Xu, K., Cui, K., Young, L.H., Hsieh, Y.K., Wang, Y.F., Zhang, J., Wan, S. (2020). Impact of the COVID-19 event on air quality in Central China. Aerosol Air Qual. Res. 20, 915-929. https://doi.org/10.42 09/aaqr.2020.04.0150 